\title{
The Extent of In Situ Urbanisation in China's County Areas
}

The Case of Fujian Province

Yu Zhu, Min Lin, Liyue Lin and Jinmei Chen

\section{(2) OpenEdition}

\section{Journals}

Electronic version

URL: http://journals.openedition.org/chinaperspectives/6263

DOI: 10.4000/chinaperspectives.6263

ISSN: 1996-4617

\section{Publisher}

Centre d'étude français sur la Chine contemporaine

Printed version

Date of publication: 1 September 2013

Number of pages: 43-52

ISSN: 2070-3449

\section{Electronic reference}

Yu Zhu, Min Lin, Liyue Lin and Jinmei Chen, « The Extent of In Situ Urbanisation in China's County Areas », China Perspectives [Online], 2013/3 | 2013, Online since 01 September 2016, connection on 28 October 2019. URL : http://journals.openedition.org/chinaperspectives/6263 ; DOI : 10.4000/ chinaperspectives.6263 


\title{
The Extent of In Situ Urbanisation
}

\section{in China's County Areas:}

\author{
The case of Fujian Province
}

\author{
YU ZHU, MIN LIN, LIYUE LIN, AND IINMEI CHEN
}

\begin{abstract}
By developing and using indexes reflecting "quasi-urban" status, this paper attempts to quantitatively estimate the "invisible" contribution of in situ urbanisation to the overall urbanisation process in the county areas of Fujian Province. The results show that the urbanisation level of the county areas in Fujian Province would be significantly increased if the urban characteristics resulting from in situ urbanisation were fully reflected, suggesting that the conventional urban statistics seriously underestimate the true extent of rural-urban transformation in the county areas. Furthermore, such underestimation is more serious in the coastal areas with most dynamic socioeconomic development, and thus distorts the true picture of the spatial pattern of rural-urban transformation. The paper explores the implications of the above results for the understanding of China's urbanisation process, suggesting that rural-urban transformation and the corresponding planning practice in China should be conceptualised in the context of blurred rural-urban distinction and more important roles for rural areas in the urbanisation process.
\end{abstract}

KEYWORDS: in situ urbanisation, quasi-urbanisation, urbanisation level, county areas, Fujian Province.

T he emergence and development of in situ urbanisation has been one of the major characteristics of China's urbanisation process since the 1980s. ${ }^{(1)}$ As opposed to the conventional city-based urbanisation dominated by rural-urban migration, in situ urbanisation is a phenomenon where rural settlements and their populations transform themselves into urban or quasi-urban settlements without much geographical relocation of the residents. It started as early as in the 1970s in the form of commune and brigade enterprises, (2) and has brought tremendous structural and physical changes to vast rural areas in the following decades, leading to increasingly blurred distinctions between urban and rural settlements in China, especially in the densely populated coastal areas. It has also greatly promoted the development of some 20,000 small towns in China, containing more than 100 million people engaged in rural non-agricultural activities and their family members. ${ }^{\left({ }^{3}\right)}$ Such a pattern of urbanisation has been widely identified in China, especially in the coastal area of Fujian Province, the Pearl River Delta region, and the Yangtze River Delta region, although alternative terms to "in situ urbanisation," such as "rural urbanisation" and "urbanisation from below," have also been used to conceptualise it from different perspectives. (4) Clearly, a complete understanding of China's urbanisation process will not be achieved if in situ urbanisation is not incorporated into the overall picture.

However, the widespread phenomenon of in situ urbanisation in China's overall urbanisation has not been well recognised, and this has much to do with the inadequacy of the dichotomous approach, which is still dominant in conceptualising urbanisation and in compiling urban statistics both in China and internationally. ${ }^{(5)}$ Under such an approach, settlements and their populations are classified into two categories, namely either urban or rural, and it is assumed that the distinction between the two categories is clearcut. Only those settlements and their populations strictly meeting the official urban criteria can be recognised as urban and thus included in official urban statistics; however, differences and changes within each of the two categories, including those resulting from in situ transformation of rural settlements and their populations, will not be reflected in the official statistics. Such an approach is still used by the National Bureau of Statistics of China in its recent stipulations concerning urban and rural definitions in statistics. ${ }^{(6)}$ According to the stipulations, China's territory is divided into urban

This paper is based on the research results of the project "Zhongguo renkou jiudi chengzhenhua de yanbian yu duice yanjiu" (A study on the evolution of China's in situ urbanisation and its policy implications) funded by the National Social Science Foundation of China (NSSFC; project code 07BRK007). The complete results of the project are published in Yu Zhu, Xinhua Qi, Guodong Wang, Liyue Lin and Min Lin, Zhongguo de jiudi chengzhenhua: Lilun yu shizheng (China's in situ urbanisation: Theories and empirical evidence), Beijing, Science Press, 2012. The authors would like to thank NSSFC for its support to the project, and Science Press for allowing the authors to use some materials of the book in the paper.

1. Yu Zhu, "'Formal' and 'Informal Urbanisation' in China:Trends in Fujian Province," Third World Planning Review, Vol. 20, No. 3, 1998, pp. 267-284; Yu Zhu, New Paths to Urbanisation in China: Seeking More Balanced Patterns, New York, Nova Science Publishers, 1999.

2. See Xiaotong Fei, "Xiao chengzhen, da wenti" (Small towns, big issues), Liaowang (Outlook), No. 3, 1984, pp. 11-13.

3. Yu Zhu, "Changing Urbanisation Processes and In Situ Rural-Urban Transformation: Reflections on China's Settlement Definitions," in Tony Champion and Graeme Hugo (eds.), New Forms of Urbanisation: Beyond the Urban-Rural Dichotomy, Aldershot, Ashgate, 2004, pp. 207-228.

4. See for examples John Friedmann, China's Urban Transition, Minneapolis, University of Minnesota Press, 2005; Gregory Eliyu Guldin, Farewell to Peasant China: Rural Urbanisation and Social Changes in the Late Twentieth Century, Armonk, NY, M. E. Sharpe, 1997; Andrew Marton, China's Spatial Economic Development: Restless Landscapes in the Lower Yangzi Delta, London, Routledge, 2000; Laurence J. C. Ma, and Ming Fan, "Urbanisation From Below: The Growth of Towns in Jiangsu, China," Urban Studies, Vol. 31, No. 10, 1994, pp. 1625-1645; Xue-qiang Xu and Si-ming Li, (1990), "China's Open Door Policy and Urbanisation in The Pearl River Delta Region," International Journal of Urban and Regional Research, Vol. 14, No.1, 1990, pp. 49-69; Yu Zhu, "In Situ Urbanisation in Rural China: Case Studies from Fujian Province," Development and Change, Vol. 31, No. 2, 2000, pp. 413-434.

5. Yu Zhu, New Paths to Urbanisation in China: Seeking More Balanced Patterns, op. cit;:Tony Champion and Graeme Hugo (eds.), New Forms of Urbanisation: Beyond the Urban-Rural Dichotomy, op. cit.

6. See Guojia Tongjiju Sheguansi (Department of Administration for Statistical Design, National Bureau of Statistics of China): Tongjishang huafen chengxiang de guiding (Stipulations concerning urban and rural definitions in statistics), www.stats.gov.cn/tjbz/t20061018_402603208.htm (accessed on 27 August 2012). 


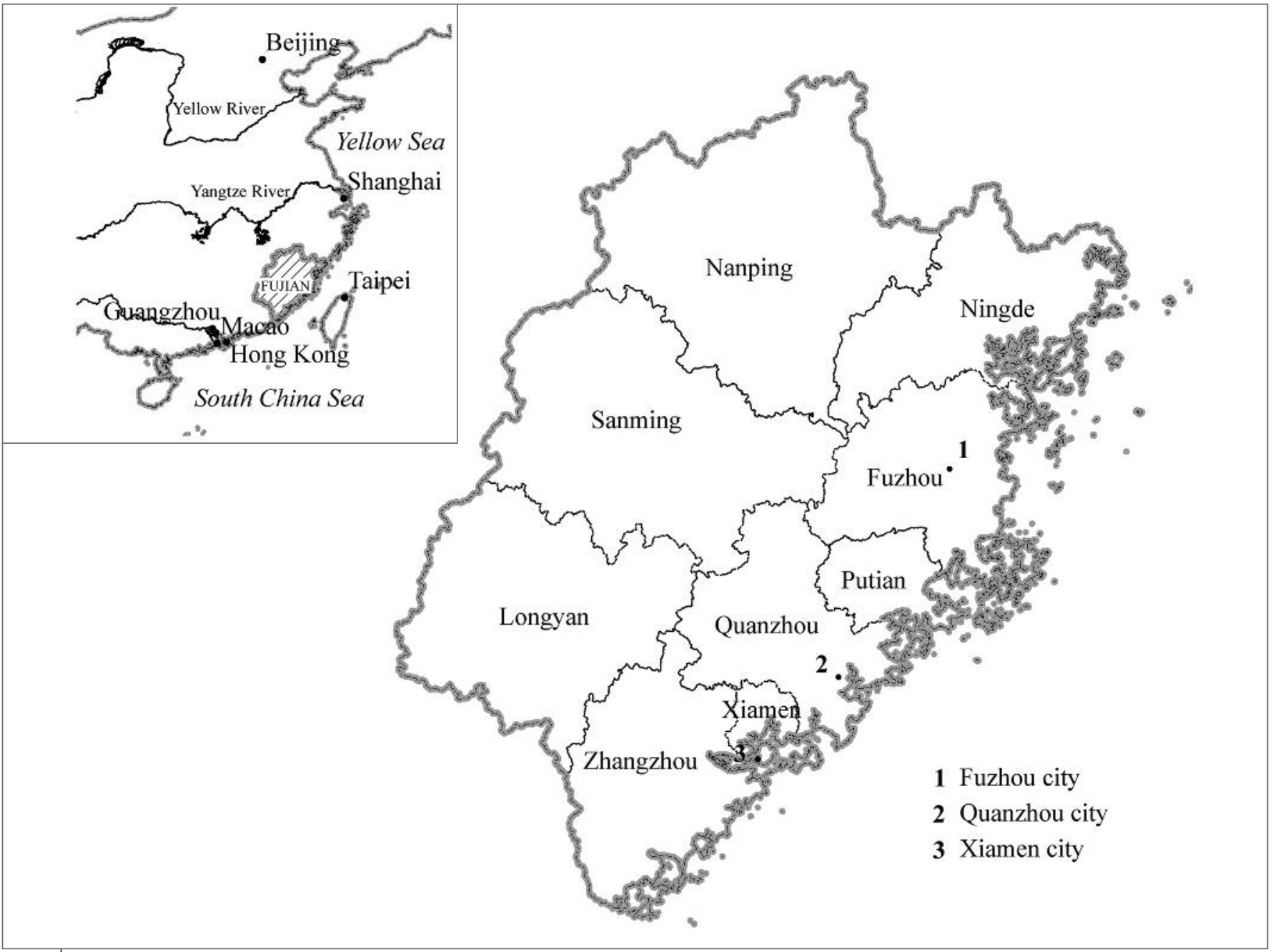

Map 1 - Location of Fujian Province, its municipalities, and selected cities. Source: Author's work

and rural areas. The urban areas refer to the neighbourhood committees and other areas within or connected to the built-up areas of the seats of city district governments (in the case of cities divided into sub-districts), the city governments (in the case of cities not divided into sub-district), the county governments, and the town governments; and the isolated special areas of industrial and mining districts, development zones, research institutions, higher education institutions, and the seats of farms and tree farms, which are not within or connected to the built-up areas of any government seats but each of which has a permanent population of more than 3,000. All other areas are referred to as rural areas. Statistics produced according to the above stipulations cannot fully reflect the enormous changes of China's rural areas in terms of population densities, employment structure, and physical environment caused by in situ urbanisation, leading to a serious under-estimation of the true extent of rural-urban transformation in China.

Examined in an international context, in situ urbanisation is not a phenomenon unique to China. As early as in the late 1980s, Terry McGee and his colleagues identified the in situ transformation of quasi-urban settlements and the increasingly important role of local non-agricultural activities in rural-urban transformation in what they termed desakota regions in the areas adjacent to some Asian mega-cities. Based on this kind of phenomenon, McGee and Ginsburg further proposed the concept of "settlement transition," which involves "the urbanisation of the countryside without massive rural-urban migration." (7) Early this century, Mohammad A. Qadeer has also identified a "largely unacknowledged" form of urbanisation in vast rural areas of India, Pakistan, and Bangladesh, where the in-place growth of population results in densities that equal or exceed the urban threshold of 400 persons per $\mathrm{km}^{2}$, comparable to the population densities in exurbs of Western cities such as Los Angeles, New York, or Toronto. ${ }^{\left({ }^{8}\right)}$ Calling such rural regions "ruralopolises," (9) Qadeer points out that the unprecedented high population density is "the transforming force that invests rural regions with urban spatial characteristics," leading to the emergence of "a hybrid settlement system that is spatially urban." (10)

Given the widespread existence of in situ urbanisation not only in China but also in other parts of the world, developing a method to quantitatively reveal its position in the overall urbanisation process is of great significance.

7. Norton Ginsburg, "Preface," in Norton Ginsburg, Bruce Koppel, and T. G. McGee (eds.), The Extended Metropolis: Settlement Transition in Asia, Honolulu, University of Hawaii Press, 1991, pp. xiii-xviii; Terry. G. McGee, "The Emergence of Desakota Regions in Asia: Expanding A Hypothesis," in Norton Ginsburg, Bruce Koppel, and Terry. G. McGee (eds.), The Extended Metropolis: Settlement Transition in Asia, op. cit., pp. 3-25.

8. Mohammad A. Qadeer, "Urbanisation by Implosion," Habitat International, Vol. 28, No. 1, 2004, pp. 1-12.

9. Mohammad A. Qadeer, "Ruralopolises: The Spatial Organisation and Residential Land Economy of High-Density Rural Regions in South Asia," Urban Studies, Vol. 37, No. 9, 2000, pp. 1583-1603.

10. Mohammad A. Qadeer, "Urbanisation by implosion," op. cit. 


\begin{tabular}{|l|c|c|c|c|c|}
\hline & 2000 & 2005 & 2006 & 2007 & 2008 \\
\hline Share of non-agricultural employment in percentage $(\mathrm{N})$ & 53.2 & 62.4 & 64.8 & 67.3 & 68.9 \\
\hline Share of urban population in percentage $(\mathrm{U})$ & 42.0 & 47.3 & 48.0 & 48.7 & 49.9 \\
\hline N/U & 1.26 & 1.32 & 1.35 & 1.38 & 1.38 \\
\hline
\end{tabular}

Source: 2000 census data of Fujian Province; Fujian Statistical Yearbook (2006, 2007, 2008, 2009); Fujian Socioeconomic Yearbook (2008)

County areas, (11) which are mostly "rural" under China's dichotomous administrative system, are the focus of this study. Based on the case of Fujian Province (Map 1), which is among the most developed regions in terms of in situ urbanisation in China as mentioned earlier, this paper attempts to create and use indexes of "quasi-urban ratio" and "quasi-urban population" to quantify in situ urbanisation and to reveal its "invisible" contribution to the overall urbanisation process. It is hoped that such an exercise will contribute to the effort of incorporating in situ urbanisation into the analysis of the overall urbanisation process, thus achieving a more complete understanding of China's urbanisation process in the reform era.

\section{The accumulation of urban elements in in situ urbanisation: Processes and major dimensions}

As Champion and Hugo point out, "The fundamental distinction between urban and rural places is normally in terms of continuously built-up area, population density, and the economic and political functions carried out in those areas." (12) One of the most important aspects of in situ urbanisation in Fujian Province has been the development of non-agricultural activities in rural areas in the form of township and village enterprises (TVES). ${ }^{(13)}$ This has brought the secondary and tertiary sectors of the economy, which are considered to be among the most important urban functions, down to the lowest levels of the settlement hierarchy, causing fundamental changes in the employment structure in the rural settlements, and even changes in administrative jurisdiction as a result of the emergence of an increasing number of newly designated cities and towns. ${ }^{(14)}$ An important result of the above transformation is the increasing share of rural residents engaged in non-agricultural activities, which constitutes an important basis for the formation of quasi-urban populations.

This in situ urbanisation can be strongly linked to high population density and the development of continuously built-up areas. Population density had already existed in the coastal areas of Fujian Province well before the above mentioned economic and employment transformation. ${ }^{(15)}$ Villages with a population of 2,000 persons were common, and the even bigger 片 村 (piancun), i.e., incorporated villages formed through the expansion and interconnection of these villages, had been observed before the 1980s. ${ }^{(16)}$ As a result, the population density of the 27 coastal county areas in the 2000 census was as high as 663 persons per square kilometre, much higher than 400 persons per square kilometre, which is considered as an almost universal criterion for defining urban settlement in the world. (17) Therefore, although many settlements in these areas are still regarded as rural, they have already attained urban population size and density. ${ }^{(18)}$

Starting in the latter half of the 1990s, the rural non-agricultural enterprises in Fujian's county areas, most of which were TVEs (rural township and village enterprises), adopted more concentrated development patterns. (19) They moved to investment zones, industrial zones, and development zones, some of which are part of the built-up areas of designated towns due to their expansion. The development of rural non-agricultural activities also created the demand and provided capital for the development of public facilities, infrastructure, and service sectors, and changed the way of life of local rural residents. (20)

Despite the significant accumulation of urban elements in the county areas of Fujian Province mentioned above, they are not well captured by the official urban statistics. This is partly reflected in Table 1, showing the ratio of the share of non-agricultural employment to the share of urban population (N/U) for Fujian Province. The higher the N/U value is, the

11. Following common practice in China, "county areas" (xianyu) refer to areas of counties (xian) and so-called county-level cities (xianjishi), both of which are county-level administrative units under China's administrative system. A county can be designated as a county-level municipality when it meets certain economic, financial, and population criteria; however, a county-level municipality is still similar to a county in rural-urban classification in the sense that village committees are still the dominant lowest-level administrative units in their areas. This is in contrast to the noncounty areas at the same administrative level, namely districts of prefecture-level municipalities, where the proportion of urban administrative units, namely residents' committees, are much higher, and often dominant, as the lowest-level administrative units in their areas. For more details on China's urban and rural administrative system and the criteria for the designation of countylevel municipalities, see Yu Zhu, "Changing Urbanisation Processes and In Situ Rural-Urban Transformation: Reflections on China's Settlement Definitions," op. cit.

12. Tony Champion and Graeme Hugo (eds.), New Forms of Urbanisation: Beyond the Urban-Rural Dichotomy, op. cit., p. 9.

13. Kwan-yiu Wong and Shimou Yao, "Urban Development," in Yue-Man Yeung and David K. Y. Chu (eds.), Fujian: A Coastal Province in Transition and Transformation, Hong Kong, The Chinese University Press, 2000, pp. 285-304; Yu Zhu, New Paths to Urbanisation in China: Seeking More Balanced Patterns, op. cit:; Yu Zhu, "Changing Urbanisation Processes and In Situ Rural-Urban Transformation: Reflections on China's Settlement Definitions," op. cit:; Yu Zhu, Xinhua Qi, Huaiyou Shao, and Kaijin He, "The Evolution of China's In Situ Urbanisation and Its Planning and Environmental Implications: Case Studies from Quanzhou Municipality," in Alex de Sherbinin, Atiqur Rahman, Alisson F. Barbieri, J.C. Fotso, and Yu Zhu (eds.), Urban Population-Development-Environment Dynamics in the Developing World: Case Studies and Lessons Learned, Paris, CICRED, 2009, Pp. 213-245.

14. Yu Zhu, "'Formal' and 'informal urbanisation' in China: Trends in Fujian Province," op. cit.; Yu Zhu, "Beyond Large-City-Centered Urbanisation: In Situ Transformation of Rural Areas in Fujian Province," Asia-Pacific View Point, Vol. 43, No.1, 2002, pp. 9-22.

15. Yu Zhu, New Paths to Urbanisation in China: Seeking More Balanced Patterns, op. cit., pp. 160162.

16. Jiayuan Chen and Gongmian Huang (eds.), Fujiansheng jingji dili (The economic geography of Fujian Province), Beijing, Xinhua Publishing House, 1991, pp. 40-44; Yu Zhu, New Paths to Urbanisation in China: Seeking More Balanced Patterns, op. cit., pp. 160-162.

17. Mohammad A. Qadeer, "Ruralopolises: The Spatial Organisation and Residential Land Economy of High-Density Rural Regions in South Asia," op. cit;; Mohammad A. Qadeer, "Urbanisation by Implosion," op. cit.

18. Yu Zhu, Xinhua Qi, Huaiyou Shao, and Kaijin He, "The Evolution of China's In Situ Urbanisation and Its Planning and Environmental Implications: Case Studies from Quanzhou Municipality," op. cit.

19. Yu Zhu, "Changing Urbanisation Processes and In Situ Rural-Urban Transformation: Reflections on China's Settlement Definitions," op. cit:; Yu Zhu, Xinhua Qi, Huaiyou Shao, and Kaijin He, "The Evolution of China's In Situ Urbanisation and Its Planning and Environmental Implications: Case Studies from Quanzhou Municipality," op. cit.

20. Yu Zhu, "Changing Urbanisation Processes and In Situ Rural-Urban Transformation: Reflections on China's Settlement Definitions," op. cit. 
stronger the contrast between the high proportion of non-agricultural employment and the low level of urbanisation, and thus the less sufficient official urban statistics are in reflecting the extent of rural-urban transformation. As can be seen in Table 1, such a contrast is evident in Fujian. Furthermore, as Table 1 demonstrates, a widening gap between the proportion of non-agricultural employment and the proportion of urban population can be observed.

A large proportion of the rural population in these areas is also involved in the other two dimensions of rural-urban transformation. A method needs to be developed to quantitatively capture such quasi-urban characteristics, measure the gap between them and the fully developed urban characteristics, and then calculate the size of the population with such quasi-urban characteristics.

\section{Quantifying the invisible roles of in situ urbanisation}

We can estimate the size of the quasi-urban population in a county area based on the size of its rural population engaged in non-agricultural activities. Such estimation involves two main steps. First, as the rural population is not fully urban according to official urban criteria, its size needs to be adjusted (reduced) by being multiplied by a quasi-urban ratio reflecting its degree of urbanity, or the degree of accumulation of urban characteristics; second, we assume that the dependents of the rural population engaged in non-agricultural activities possess the same urban characteristics, and should be included in the estimation of the size of the quasi-urban population. After the above two-step procedure, we can derive the size of the quasi-urban population and its proportion of the total population, and then add it to the urban population officially recognised in statistics, incorporating the results of in situ urbanisation. The above procedure is reflected in the following formula:

Formula 1 - Adjusted urban population in county areas

$$
I U=\frac{U P+N \sum_{1}^{n} A_{i} E_{i} \times(1+C)}{P}(i=1,2, \ldots, n)
$$

- IU is the revised urban proportion of the population of a county area,

- UP $(A)$ is the number of urban residents officially recognised in urban statistics,

- $\mathrm{N}$ is the number of rural residents engaged in non-agricultural activities,

- $E_{i}$ is the quasi-urban ratio of the number $i$ urban characteristic used to adjust the number of rural residents engaged in non-agricultural activities to derive the size of the quasi-urban population, $A_{i}$ is the weight of $\mathrm{E}_{\mathrm{i}}$,

- $C$ is the dependent ratio of the quasi-urban population,

- $P$ is the total number of a county area's residents,

- $\sum A_{i} E_{i}$ is the overall quasi-urban ratio for the rural residents engaged in non-agricultural activities.

The calculation of $E_{i}, A_{i}$, and $C$ are elaborated in the Appendix, and data for 2007 are used in the calculation.
Based on formula 1, Table 2 presents the proportion of the officially recognised urban population $(A)$, which is defined according to the stipulations of China's National Bureau of Statistics concerning urban and rural delineation mentioned earlier, and obtained directly from Fujian Statistical Yearbook (2008); the proportion of the quasi-urban population (B), derived from formula 1 ; and the revised proportion of urban population, namely the value of IU from formula 1 (C), which incorporates both the proportion of the officially recognised urban population and the proportion of the quasi-urban population, for each county area of Fujian Province and the total area of all its counties.

\section{Relative roles of in situ urbanisation and officially recognised urbanisation in Fujian's county areas}

The most important finding from the above estimation is that the conventional urban statistics seriously under-estimate the true extent of ruralurban transformation. From the 2008 Fujian Statistical Yearbook one can see that the officially recognised urban population of Fujian's 58 county areas was 9,101,100 in 2007, accounting for $36.5 \%$ of the total population. This suggests a predominantly rural picture with a low urbanisation rate. However, if in situ urbanisation is incorporated into the overall picture, the situation is quite different. The results of the above estimation suggest that the quasi-urban population of Fujian's county areas amounted to 6,208,000 in 2007 , accounting for $24.9 \%$ of the total population. If this quasi-urban population is included, then we can derive a revised total urban population of $15,309,100$, and a revised urbanisation rate of $61.4 \%$ for the county areas of Fujian Province. This figure is certainly more consistent with the reality observed on the ground - that rural industrialisation is widespread and well developed - and therefore more accurately reflects the true extent to which the settlements and their populations in Fujian's county areas have been transformed into urban or quasi-urban locales. In fact, comparing the revised urbanisation rate and the officially recognised urbanisation rates, one can infer that $40.55 \%$ of the rural-urban transformation process in Fujian's county areas is "hidden" behind the official urban statistics.

Examining different combinations of the proportions of the officially recognised urban population and the quasi-urban population in county areas, one can obtain more detailed insights into the relative roles of both in situ urbanisation and officially recognised urbanisation in the overall urbanisation process in Fujian's county areas. Such combinations can be divided into four types (Map 2). The first type relates to county areas where the proportions of both the officially recognised urban population and of the quasi-urban population were higher than the corresponding provincial averages for county areas. They are all located in Fujian's south-eastern coastal area, with Jinjiang near Quanzhou City as a typical example. This area is well known for the development of in situ urbanisation driven by the development of industrial township and village enterprises, which started in the early 1980s. ${ }^{(21)}$ In the long process of in situ development, two dimensions of official urban criteria, namely non-agricultural employment and high population densities, had long been met in many of these rural settlements. In recent development, the expansion of public facilities and infrastructure from the built-up

21. Yu Zhu, "In Situ Urbanisation in Rural China: Case Studies from Fujian Province," op. cit.; Yu Zhu, "Beyond Large-City-Centered Urbanisation: In Situ Transformation of Rural Areas in Fujian Province," op. cit. 
Table 2 - Proportions of officially recognised urban population and quasi-urban population in Fujian's county areas, 2007

\begin{tabular}{|c|c|c|c|c|}
\hline $\begin{array}{l}\text { Prefecture-level } \\
\text { Municipalities }\end{array}$ & County Area & $\begin{array}{l}\text { Proportion of the officially } \\
\text { recognised urban } \\
\text { population (A) }\end{array}$ & $\begin{array}{l}\text { Proportion of the } \\
\text { quasi-urban population } \\
\text { (B) }\end{array}$ & $\begin{array}{l}\text { Revised proportion } \\
\text { of urban population } \\
\qquad(C)=(A)+(B)\end{array}$ \\
\hline \multirow{8}{*}{ Fuzhou } & Minhou County & $27.71 \%$ & $26.06 \%$ & $53.78 \%$ \\
\hline & Lianjiang County & $33.58 \%$ & $28.72 \%$ & $62.30 \%$ \\
\hline & Luoyuan County & $31.00 \%$ & $19.03 \%$ & $50.03 \%$ \\
\hline & Minqing County & $27.04 \%$ & $16.90 \%$ & $43.95 \%$ \\
\hline & Yongtai County & $26.22 \%$ & $15.96 \%$ & $42.18 \%$ \\
\hline & Pingtan County & $18.94 \%$ & $22.98 \%$ & $41.92 \%$ \\
\hline & Fuqing Municipality & $31.85 \%$ & $34.25 \%$ & $66.09 \%$ \\
\hline & Changle Municipality & $33.79 \%$ & $45.06 \%$ & $78.85 \%$ \\
\hline Putian & Xianyou County & $26.80 \%$ & $36.36 \%$ & $63.16 \%$ \\
\hline \multirow{10}{*}{ Sanming } & Mingxi County & $31.28 \%$ & $13.04 \%$ & $44.32 \%$ \\
\hline & Qingliu County & $29.62 \%$ & $11.18 \%$ & $40.80 \%$ \\
\hline & Ninghua County & $23.41 \%$ & $16.34 \%$ & $39.75 \%$ \\
\hline & Datian County & $27.29 \%$ & $10.40 \%$ & $37.69 \%$ \\
\hline & Youxi County & $24.29 \%$ & $12.32 \%$ & $36.61 \%$ \\
\hline & Sha County & $47.30 \%$ & $13.65 \%$ & $60.95 \%$ \\
\hline & Jiangle County & $39.29 \%$ & $12.48 \%$ & $51.77 \%$ \\
\hline & Taining County & $36.19 \%$ & $10.83 \%$ & $47.02 \%$ \\
\hline & Jianning County & $24.48 \%$ & $11.08 \%$ & $35.56 \%$ \\
\hline & Yong'an Municipality & $57.80 \%$ & $7.40 \%$ & $65.20 \%$ \\
\hline \multirow{7}{*}{ Quanzhou } & Huian County & $40.90 \%$ & $52.59 \%$ & $93.49 \%$ \\
\hline & Anxi County & $30.00 \%$ & $42.17 \%$ & $72.17 \%$ \\
\hline & Yongchun County & $38.49 \%$ & $13.64 \%$ & $52.13 \%$ \\
\hline & Dehua County & $51.31 \%$ & $12.49 \%$ & $63.79 \%$ \\
\hline & Shishi Municipality & $73.50 \%$ & $20.73 \%$ & $94.23 \%$ \\
\hline & Jinjiang Municipality & $46.60 \%$ & $40.22 \%$ & $86.81 \%$ \\
\hline & Nan'an Municipality & $40.60 \%$ & $45.20 \%$ & $85.80 \%$ \\
\hline \multirow{9}{*}{ Zhangzhou } & Yunxiao County & $38.99 \%$ & $19.79 \%$ & $58.78 \%$ \\
\hline & Zhangpu County & $35.4 \%$ & $21.91 \%$ & $57.31 \%$ \\
\hline & Zhaoan County & $22.40 \%$ & $33.93 \%$ & $56.33 \%$ \\
\hline & Changtai County & $41.98 \%$ & $14.55 \%$ & $56.53 \%$ \\
\hline & Dongshan County & $22.52 \%$ & $34.59 \%$ & $57.10 \%$ \\
\hline & Nanjing County & $36.00 \%$ & $14.31 \%$ & $50.31 \%$ \\
\hline & Pinghe County & $32.20 \%$ & $18.53 \%$ & $50.72 \%$ \\
\hline & Hua'an County & $32.91 \%$ & $12.01 \%$ & $44.92 \%$ \\
\hline & Longhai Municipality & $40.00 \%$ & $27.11 \%$ & $67.11 \%$ \\
\hline \multirow{9}{*}{ Nanping } & Shunchang County & $42.11 \%$ & $11.43 \%$ & $53.54 \%$ \\
\hline & Pucheng County & $37.00 \%$ & $10.01 \%$ & $47.01 \%$ \\
\hline & Guangze County & $34.29 \%$ & $11.51 \%$ & $45.80 \%$ \\
\hline & Songxi County & $32.61 \%$ & $12.52 \%$ & $45.13 \%$ \\
\hline & Zhenghe County & $31.31 \%$ & $12.86 \%$ & $44.16 \%$ \\
\hline & Shaowu Municipality & $61.19 \%$ & $7.09 \%$ & $68.28 \%$ \\
\hline & Wuyishan Municipality & $50.19 \%$ & $8.58 \%$ & $58.76 \%$ \\
\hline & Jian'ou Municipality & $37.99 \%$ & $11.10 \%$ & $49.09 \%$ \\
\hline & Jianyang Municipality & $53.21 \%$ & $8.26 \%$ & $61.48 \%$ \\
\hline \multirow{6}{*}{ Longyan } & Changting County & $32.69 \%$ & $14.58 \%$ & $47.27 \%$ \\
\hline & Yongding County & $29.59 \%$ & $16.50 \%$ & $46.10 \%$ \\
\hline & Shanghang County & $24.20 \%$ & $18.25 \%$ & $42.45 \%$ \\
\hline & Wuping County & $25.61 \%$ & $16.26 \%$ & $41.87 \%$ \\
\hline & Liancheng County & $31.49 \%$ & $13.73 \%$ & $45.22 \%$ \\
\hline & Zhangping Municipality & $39.60 \%$ & $10.35 \%$ & $49.95 \%$ \\
\hline \multirow{8}{*}{ Ningde } & Xiapu County & $36.29 \%$ & $19.08 \%$ & $55.37 \%$ \\
\hline & Gutian County & $30.00 \%$ & $14.63 \%$ & $44.63 \%$ \\
\hline & Pingnan County & $28.71 \%$ & $12.95 \%$ & $41.66 \%$ \\
\hline & Shouning County & $24.94 \%$ & $16.39 \%$ & $41.32 \%$ \\
\hline & Zhouning County & $29.02 \%$ & $14.78 \%$ & $43.79 \%$ \\
\hline & Zherong County & $32.86 \%$ & $14.81 \%$ & $47.67 \%$ \\
\hline & Fuan Municipality & $44.70 \%$ & $14.50 \%$ & $59.20 \%$ \\
\hline & Fuding Municipality & $47.20 \%$ & $14.26 \%$ & $61.46 \%$ \\
\hline Total & & $36.51 \%$ & $24.90 \%$ & $61.41 \%$ \\
\hline
\end{tabular}




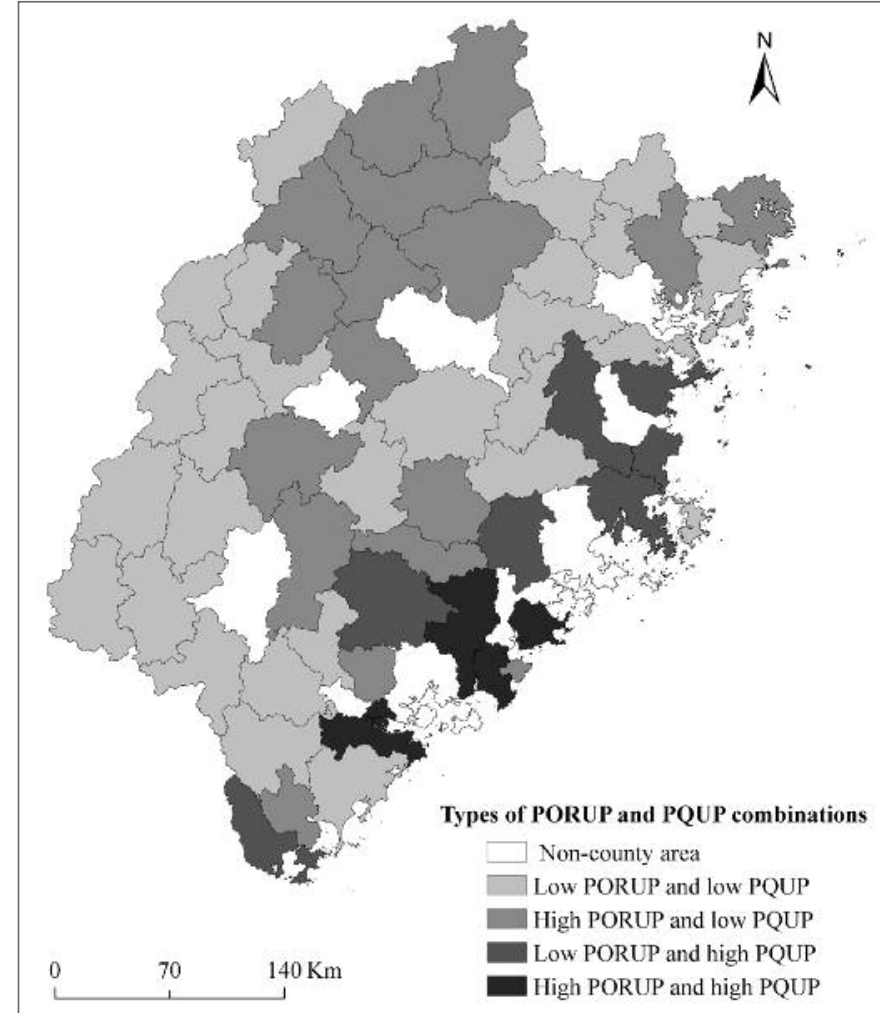

Map 2 - Four types of combinations in the proportions of the officially recognised urban population (PORUP) and the quasi-urban population (PQUP) in Fujian's county areas (2007). Source: Based on Table 2.

areas of existing towns and cities to their neighbouring villages has also fulfilled the urban criterion of continuously built-up areas. Thus after a long process of development, many originally rural settlements and their populations in these county areas have completed their rural-urban transformation in all three dimensions of rural-urban transformation mentioned earlier, leading to an increase in the proportion of the officially recognised urban population. ${ }^{(22)}$ At the same time, in situ urbanisation in other rural parts of these county areas is developing dynamically, leading to a continued increase in the proportion of the quasi-urban population.

The second type of combination is related to county areas where the proportion of the officially recognised urban population was lower than the corresponding provincial average of the county areas, but the proportion of the quasi-urban population was higher than the corresponding provincial average of the county areas. They are located in or near the coastal area, close to its major cities. County areas surrounding Fuzhou, the provincial capital of Fujian Province, such as Fuging Municipality and Changle Municipality, are typical examples. In these county areas, the early stage of rural development since the reform era was characterised by emigration (in the case of Fuqing Municipality and Changle Municipality) to other countries, including Japan, Europe, and the US, and by out-migration to other parts of China. ${ }^{(23)}$ Therefore in situ urbanisation started later and has been less developed compared to the county areas of the first type, and fewer rural settlements and populations have experienced a transformation mature enough for official recognition in urban statistics. However, since the late 1990s and early 2000s, in situ urbanisation has started to catch up in these areas, leading to a significant increase in the proportion of the quasi-urban

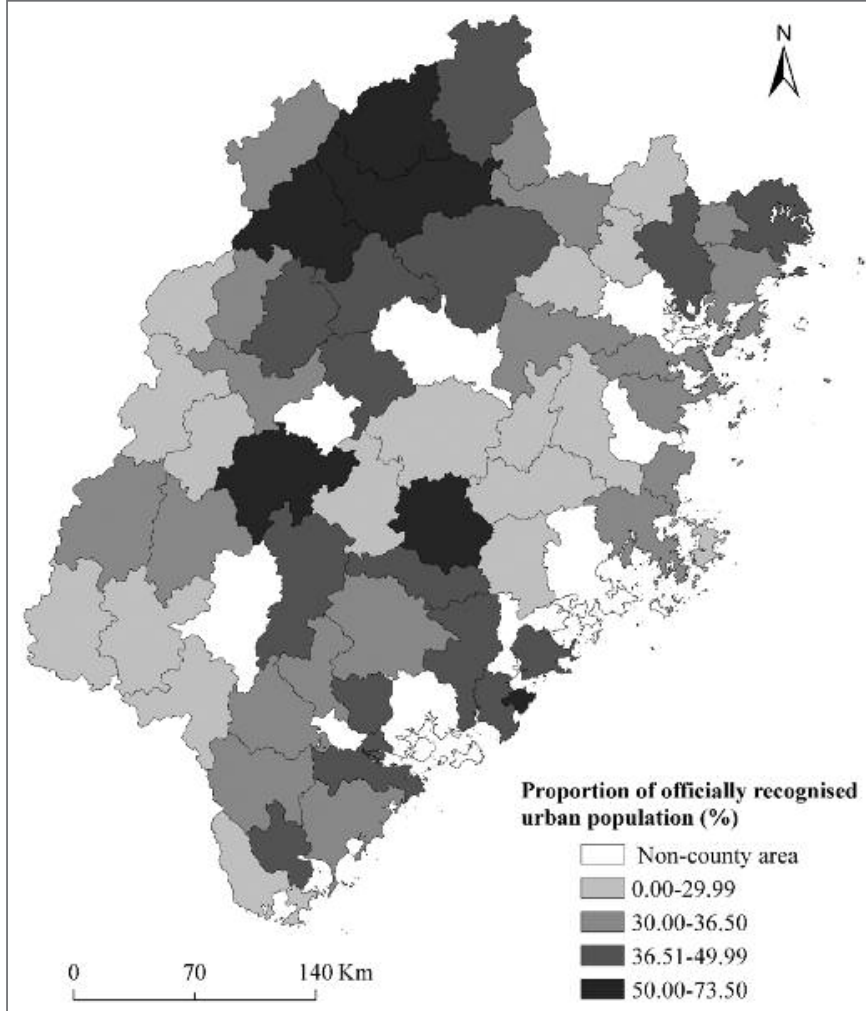

Map 3 - Proportion of officially recognised urban population in Fujian's county areas (2007).

Source: Based on Table 2 (Column A).

population. It can be expected that changes similar to those of the first type will appear in these areas in the future.

The third type of combination is related to county areas where the proportion of the officially recognised urban population was higher than the corresponding provincial average of county areas, but the proportion of the quasi-urban population was lower than the provincial average for county areas. Shaowu and Wuyishan are two examples of this type. Most of these areas are located in the inland or mountainous parts of Fujian, (24) where in situ urbanisation has not been well developed. In contrast, in these areas the designated towns, especially the towns where the seats of the county or county-level municipal governments are located, play a big role in the urbanisation process, due to their proximity to major transport systems, especially railways. Business and employment there have attracted a large number of rural residents to move to them, leading to an increase of the proportion of the officially recognised urban population. The fourth type of combination relates to county areas where the proportion of both the officially recognised urban population and of the quasi-urban population were lower than the provincial averages for county areas. Ninghua County and Datian County are two examples of

22. Yu Zhu, Xinhua Qi, Guodong Wang, Liyue Lin, and Min Lin, Zhongguo de jiudi chengzhenhua: Lilun yu shizheng (China's in situ urbanisation: Theories and empirical evidence), op. cit., pp. 110-111.

23. Yu Zhu, "In Situ Urbanisation in Rural China: Case Studies from Fujian Province," op. cit.; Frank Pieke, Pál Nyíri, Mette Thunø, and Antonella Ceccagno, Transnational Chinese: Fujianese Migrants in Europe, Stanford, Stanford University Press, 2004.

24. Shishi Municipality is an exception, as it is located in the coastal area with well-developed in situ urbanisation. It used to be part of Jinjiang Municipality, and was designated as a municipality with a small area of rural hinterland as early as the 1980s, and therefore most of its population can be easily included in the officially recognised urban statistics. 


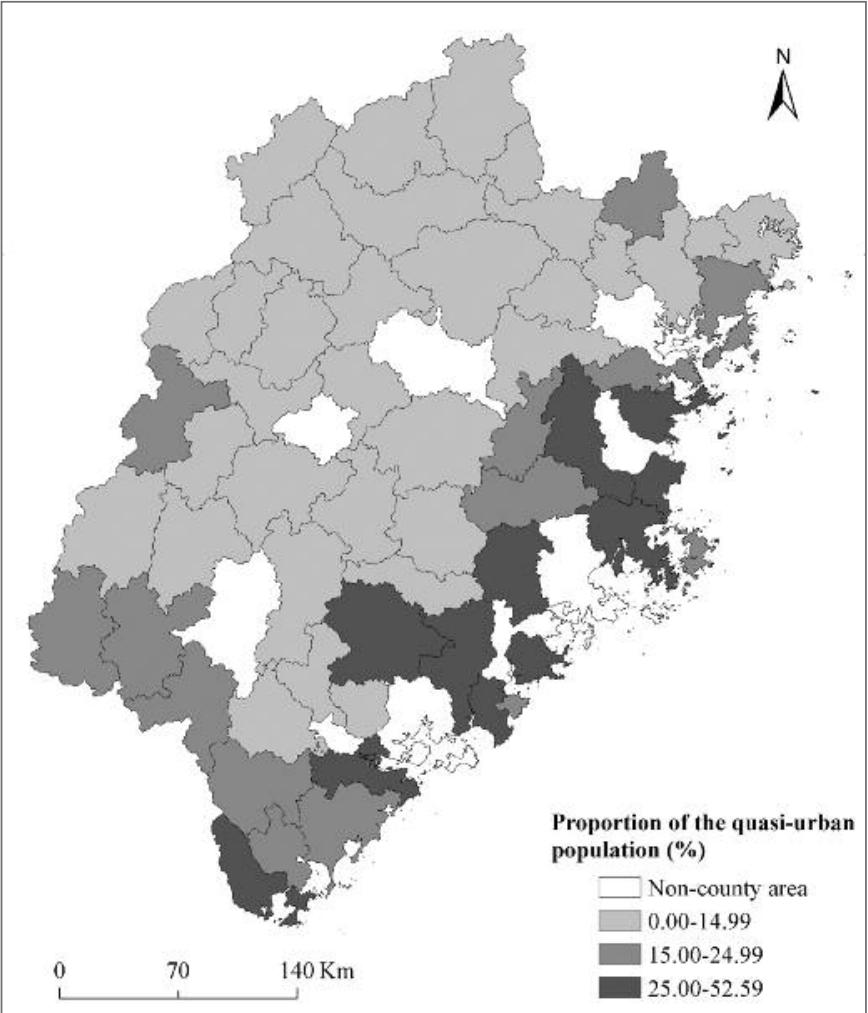

Map 4 - Proportion of the quasi-urban population in Fujian's county areas (2007). Source: Based on Table 2 (Column B).

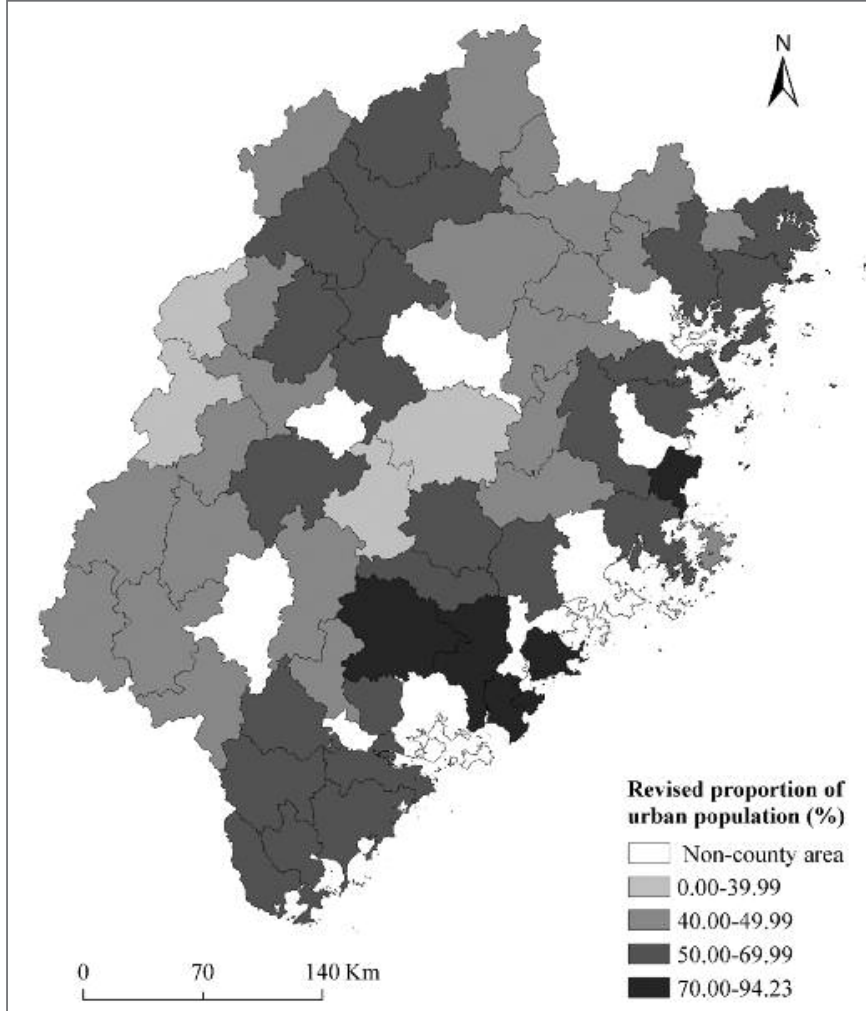

Map 5 - Proportion of revised urban population in Fujian's county areas (2007) Source: Based on Table 2 (Column C).

ulation in Fujian's county areas (Map 3), one finds that although it varies significantly among the county areas, no clear spatial pattern can be identified between coastal and inland regions. It can be calculated that the proportions of the officially recognised urban population for the former and latter were $36.5 \%$ and $36.52 \%$ respectively in 2007 .

However, the distribution of the quasi-urban population in Fujian's county areas exhibits a very different spatial pattern. As can be seen in Map 4, county areas with a high proportion of quasi-urban population are mostly located in the coastal area, except for its northern part, which is mountainous. The proportions of the quasi-urban population in 2007 were mostly above $25 \%$ in these coastal county areas, below $15 \%$ in the inland area, and from 15 to $25 \%$ in the south-western part of the province. On the whole, a clear contrast between the coastal and inland areas can be identified. It can be calculated that in the coastal areas as a whole the proportion of the quasi-urban population was $32 \%$, while that of the inland area was only $13 \%$.

Map 5 demonstrates the revised proportion of urban population in $\mathrm{Fu}$ jian's county areas by combining the officially recognised urban population and the quasi-urban population. The revised proportion of urban population in the coastal areas was $68.54 \%$ in 2007 , much higher than the $49.69 \%$ for inland areas. Since there was no significant difference between the coastal and inland areas in terms of the proportion of the officially recognised urban population, the above difference was largely caused by the difference in the proportion of the quasi-urban population

25. Yu Zhu, New Paths to Urbanisation in China: Seeking More Balanced Patterns, op. cit.

26. Yu Zhu, Xinhua Qi, Guodong Wang, Liyue Lin, and Min Lin, Zhongguo de jiudi chengzhenhua: Lilun yu shizheng (China's in situ urbanisation: Theories and empirical evidence), op. cit. 
in the coastal and inland areas. This result confirms again the important role of in situ urbanisation in the overall rural-urban transformation process and its spatial pattern. It also resolves an issue that has puzzled relevant government departments in Fujian Province for a long time, namely why the proportion of the officially recognised urban population in the coastal area of Fujian, which is economically more developed, has not been higher than in the inland part of the province. The answer is that the official urban statistics underestimate the extent of rural-urban transformation in Fujian's county areas, and thus distort the true picture of the spatial pattern of rural-urban transformation. Such a distortion has important implications for urban and regional planning in Fujian Province, and deserves close attention.

\section{Implications of in situ rural-urban transformation for urban statistics and urban planning practices}

The important status of in situ urbanisation poses great challenges not only to conventional urban statistics, but also to conventional urban planning practices. Since a similar phenomenon is widespread in China, as mentioned earlier, such challenges are by no means restricted to Fujian Province. In fact, while the growth of some major mega-cities in China such as Shanghai and Guangzhou has increasingly become the focus of urban development in China, one of its most important components and most difficult issues to deal with is in situ urbanisation of the populations of the surrounding quasi-urban areas of these cities. ${ }^{(27)}$ Since in situ urbanisation and the quasi-urban population occupy such an important position in the overall rural-urban transformation process, a more sophisticated, non-dichotomous system of settlement categories covering the whole continuum of rural-urban changes, and a new planning framework going beyond the city-centred approach and reflecting the reality of a blurred rural-urban distinction, are urgently needed.

A multidimensional scoring system can be developed to measure the degree of urbanity of all settlements, determine the settlement types, and monitor their transformation. Details of the scoring systems still need to be explored; however, the three major dimensions of in situ rural-urban transformation mentioned earlier provide guidelines for selecting the indicators and determining the criteria for different settlement categories. A settlement can be assigned a score, which can be compared to a threshold value to decide whether the locale is urban or rural. While locales identified as urban can be included in the official system of urban statistics, those settlements with scores below the threshold value can be categorised as either rural or a transitional settlement type, according to their scores. In this way, all settlements with different degrees of urbanity (or rurality) can be covered by this settlement category system and monitored by the official statistics. This will effectively enable the relevant research and planning practices to be expanded to the rural end of the settlement system.

In terms of a new planning framework going beyond the city-centred approach and reflecting the reality of blurred rural-urban distinctions, an important and encouraging step has been taken in China in this regard. In October 2007, the Urban-Rural Planning Law of the People's Republic of China was promulgated. This will promote the adoption of an integrated approach in the planning of rural and urban areas, includ- ing those with well-developed in situ urbanisation. However, a careful reading of the law reveals that although it now extends its coverage to rural areas on the surface, it remains vague and inadequate in addressing planning issues caused by the blurred rural-urban distinction and the resultant increasing importance of rural localities and intensified rural-urban interaction. Many technical details still need to be worked out for the implementation of the law before in situ urbanisation can be adequately included.

This is reflected in the fact that in terms of the planning framework, there are essentially still two types of planning under the current law: namely urban planning, consisting of urban system planning, city planning, and town planning; and rural planning consisting of rural township planning and village planning. In fact, in the deliberations of the Standing Committee of the National People's Congress before the law was promulgated, some members of the standing committee pointed out that the law should not be "a simple combination of the original Urban Planning Law and the Regulations Regarding the Construction of Villages and Market Towns," and criticised the fact that the law's content on township and village planning was significantly weaker than that on city and town planning. ${ }^{(28)}$ Furthermore, the real planning practices are still overwhelmingly dominated by the needs of built-up areas; quasiurban areas or more conventional rural areas and their populations are still neglected, treated merely as a background for the planning of the built-up areas, with much less consideration of their needs in infrastructure, public utilities, land uses, and their spatial relationship with the urban cores. ${ }^{(29)}$ This is not commensurate with the fact that in situ urbanisation has created great demand for urban-like planning. Therefore, the Urban-Rural Planning Law needs to be revised to elaborate the relationships among urban system planning, city planning, town planning, township planning, and village planning, and to adopt the "city region," which covers not only the major city but also smaller cities, towns, and semi-urban and rural hinterland, which are beyond the administrative boundary of the major city but under its influence, ${ }^{(30)}$ as a planning unit, so that both the city core and its surrounding rural and quasi-rural areas under its influence can be truly included in the planning practices to accommodate the reality of the blurred rural-urban distinction. It is hoped that the important position of in situ urbanisation will serve as a catalyst to push forward the efforts of addressing the inadequacies in conventional urban statistics and urban planning practices, so that the quasi-urban areas and populace resulting from in situ urbanisation of the county areas can be truly incorporated into China's overall urban and regional planning.

27. See for example, Xuwei Hu, Yixing Zhou, and Chaolin $\mathrm{Gu}$ (eds.), Zhongguo yanhai chengzhen mijidiqu kongjian jiju yukuosan yanjiu (Studies on the spatial agglomeration and dispersion in China's coastal city-and-town concentrated areas), Beijing, Science Press, 2000

28. See http://npc.people.com.cn/GB/71673/5686795.html (accessed on 27 August 2012).

29. Yu Zhu, Xinhua Qi, Guodong Wang, Liyue Lin, and Min Lin, Zhongguo de jiudi chengzhenhua: Lilun yu shizheng (China's In Situ Urbanisation: Theories and empirical evidence), op. cit.

30. For a more detailed discussion on the concept of "city region," see UNHABITAT, State of the World Cities 2010/2011: Bridging the Urban Divide, London/Washington, D.C.: Earthscan, 2008, pp. 8-10. 


\section{Appendix: The calculation of $E_{i}, A_{i}$ and $C$ in formula (1)}

$$
I U=\frac{U P+N \sum_{1}^{n} A_{i} E_{i} \times(1+C)}{P}(i=1,2, \ldots, n)
$$

\section{The calculation of Ei}

In the formula below, if $X_{i}^{0}(i=1,2, \ldots, n)$ is the criterion for the number $i$ indicator to be fully urban, $X_{i}(i=1,2, \ldots, n)$ is the value of that indicator for a county area, then $E_{i}(i=1,2 \ldots \ldots, n)$ is the ratio of $X_{i}$ over $X_{i}^{0}$. It is the quasiurban ratio for the number $i$ indicator reflecting the number $i$ urban characteristic for the county area.

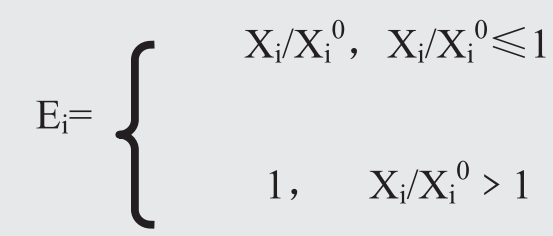

Here $0<\mathrm{E}_{\mathrm{i}} \leqslant 1 ; \quad \mathrm{i}=1,2, \ldots, \mathrm{n}$.

There are many indicators that can reflect the urban characteristics of a county area. In this paper, we adopt the three fundamental dimensions mentioned earlier that distinguish between urban and rural places, namely continuously built-up areas, population density, and the economic and political functions carried out in those areas. ${ }^{\left({ }^{31}\right)}$ We first choose the number of rural residents engaged in non-agricultural activities, which appears as $N$ in formula (1), as the first indicator to reflect the urban economic functions in a county area. As this indicator is used as the base number for estimating the size of the quasi-urban population in a county area, we no longer consider it in the calculation of the $\mathrm{E}_{\mathrm{i}}$ value. We then choose population density, which is the second fundamental dimension distinguishing urban and rural places, as a major indicator reflecting urban characteristics, and calculate its $\mathrm{E}_{\mathrm{i}}$ value accordingly.

Unfortunately, no direct indicators reflecting the third fundamental dimension of rural-urban distinction, namely continuously built-up areas, can be obtained for the county areas, and therefore we have to use indirect indicators as surrogates. Taking Sijun Wang's similar work as the reference ${ }^{(32)}$ and considering the availability, quantifiability, and comparability of various indicators, we choose five such surrogate indicators of a built-up area, namely the proportion of villages in a county area with access to tap water, telephones, automobiles, and cable TV, and the reversed Engle coefficient ${ }^{(33)}$ of a county area. Among these five indicators, the first four reflect the fact that a built-up area normally has access to such facilities, and the last indicator, namely the reversed Engle coefficient, reflects the urban characteristics of a built-up area in terms of the lifestyle of its residents, characterised by a higher proportion of expenses in non-food consumption in comparison with rural residents. On the basis of the above selection, the $X_{i}$ values in formula (2) can be defined as follows:

$\mathrm{X}_{1}$ : the population density of rural areas in a county area (people per $\left.\mathrm{km}^{2}\right)$;
$\mathrm{X}_{2}$ : the proportion of villages with access to tap water in a county area;

$X_{3}$ : the proportion of villages with access to telephones in a county area;

$\mathrm{X}_{4}$ : the proportion of villages with access to automobiles in a county area;

$X_{5}$ : the proportion of villages with access to cable TV in a county area;

$X_{6}$ : the reversed Engle coefficient, namely 1 minus the Engle coefficient of the rural areas of a county area.

In calculating the $\mathrm{E}_{\mathrm{i}}$ value, $\mathrm{X}_{\mathrm{i}}{ }^{\mathrm{O}}$ also needs to be determined. As 400 persons per square kilometre is considered an almost universal criterion worldwide for defining urban settlement, ${ }^{\left({ }^{34}\right)}$ we choose this value as $X_{1}{ }^{0}$. We choose the corresponding average values of Fujian's urban areas for $X_{2}$ to $X_{6}$ as the values for $X_{2}{ }^{0}$ to $X_{6}{ }^{0}$, where $X_{2}{ }^{0}, X_{3}{ }^{0}, X_{4}{ }^{0}, X_{5}{ }^{0}$ are all equal to 100 , and $X_{6}{ }^{0}$ is $61.1 \%$ according the figure of 2007 in Fujian Statistical Yearbook. On the basis of the above values, the $\mathrm{E}_{\mathrm{i}}$ values can be calculated.

\section{The calculation of $\mathrm{Ai}$}

As can be seen in Formula (1), due to the different importance of various indicators in determining the overall quasi-urban ratio for the rural population in a county area engaged in non-agricultural activities, we need to apply a weight $\left(A_{i}\right)$ to each of the $E_{i}$ values to calculate the multiplication product of $A_{i} E_{i}$. We use the method of entropy value ${ }^{(35)}$ to determine the weights. In such a method, a smaller entropy value of an indicator suggests a larger variation of the indicator's values and more useful information provided by the indicator, and therefore this indicator should be assigned a higher weight. On the other hand, a larger entropy value suggests a smaller variation of the indicator's values and less useful information provided by the indicator, and therefore this indicator should be assigned a lower weight. Thus the method of entropy value can well reflect the relative importance of the indicators in determining the overall quasi-urban ratio, as well as avoid the shortcomings of the subjective weighing method, which heavily relies on the subjective judgments of

31. Tony Champion and Graeme Hugo (eds.), New Forms of Urbanisation: Beyond the Urban-Rural Dichotomy, op. cit., p. 9.

32. Sijun Wang, Jingneng Li, and Yuncheng Zhu, Zhongguo chengshihua quyu fazhan yanjiu (A study on regional development issues of China's urbanisation), Beijing, Higher Education Press, 1996, pp. $125-127$.

33. The Engle coefficient is the proportion of family income that is spent on food consumption, and the reversed Engle coefficient is the proportion of family income that is spent on non-food consumption.

34. Mohammad A. Qadeer, "Ruralopolises: The Spatial Organisation and Residential Land Economy of High-Density Rural Regions in South Asia," op. cit. Mohammad A. Qadeer, "Urbanisation by Implosion," op. cit.

35. See Xianguang Guo, "An improved entropy value method and its application in the evaluation of economic efficiency," Xitong gongcheng yu shijian (Theories and practices of system engineering), No. 12, 1998, pp. 98-102. 
the experts involved to determining the weights of the indicators. The calculation is as follows:

(a) Standardisation of the data: $X_{i j}=\left(X_{i j}-\min \left\{X_{j}\right\}\right) /\left(\max \left\{X_{j}\right\}-\min \left\{X_{j}\right\}\right)$ $(i=1,2, \ldots m ; j=1,2 \ldots n)$;

(b) Calculation of the proportion of number $i$ value of the number $j$ indicator:

$$
\mathrm{Y}_{\mathrm{ij}}=\mathrm{X}_{\mathrm{ij}}^{\prime} / \sum_{i=1}^{m} X_{\mathrm{ij}} \quad \mathrm{i}=1,2, \ldots \mathrm{m} ; \mathrm{j}=1,2 \ldots \mathrm{n} ;
$$

(c) Calculation of the information entropies:

$$
\mathrm{e}_{\mathrm{j}}=-\mathrm{K} \sum_{i=1}^{m}\left(\mathrm{Y}_{\mathrm{ij}} \times \ln \mathrm{Y}_{\mathrm{ij}}\right)
$$

where $k=1 / \ln m \quad 0 \leq e_{j} \leq 1,(i=1,2, \ldots m ; j=1,2 \ldots n)$;

(d) Calculation of the variation coefficients: $g_{j}=1-e_{j}(j=1,2 \ldots n)$;

(e) Calculation of the weights: $j=1,2 \ldots n$ )
In the above formulas, $\max \left\{X_{j}\right\}$ and $\min \left\{X_{j}\right\}$ are the minimum and maximum values of an indicator, $m$ is the number of values for each of the indicators, which in the case of this study is 58 , the number of county areas of Fujian Province, and $n$ is 6 , the number of indicators.

Following the above procedure we calculated the values of $A_{i}$ as shown in Table 3, together with the $X_{i}^{0}$ values.

\section{The calculation of $C$}

The dependent ratio $\mathrm{C}$ in formula 1 was obtained by using the following formula:

$C(\%)=$ Number of non-employed people in rural areas of a county area / Number of employed people in the rural areas of a county area.

Applying the results of the above procedures to formula (1) and its components, we can obtain the size and proportion of the quasi-urban population and the revised proportion of the urban population (incorporating the quasi-urban population) for both Fujian's county areas as a whole and for each of the county areas in Fujian, as shown in the main text and Table 2.

\begin{tabular}{|c|c|c|c|c|c|}
\hline $\mathbf{X}_{\mathbf{i}}$ & $\mathbf{X}_{\mathbf{i}}^{0}$ & $A_{i}$ & $\mathbf{X}_{\mathbf{i}}$ & $\mathbf{X}^{0}$ & $A_{i}$ \\
\hline $\begin{array}{l}\text { Population density of rural areas } \\
\left.\text { (Persons } / \mathrm{km}^{2}\right) \\
\qquad \mathrm{X}_{1}\end{array}$ & 400 & 0.6512 & $\begin{array}{l}\text { Proportion of villages with access to } \\
\text { automobiles (\%) } \\
\qquad \mathrm{X}_{4}\end{array}$ & 100 & 0.0393 \\
\hline $\begin{array}{l}\text { Proportion of villages with access to } \\
\text { tap water (\%) } \\
\qquad \mathrm{X}_{2}\end{array}$ & 100 & 0.0867 & $\begin{array}{l}\text { Proportion of villages with access to } \\
\text { cable TV (\%) } \\
\qquad X_{5}\end{array}$ & 100 & 0.0392 \\
\hline $\begin{array}{l}\text { Proportion of villages with access to } \\
\text { telephones (\%) } \\
\qquad \mathrm{X}_{3}\end{array}$ & 100 & 0.0377 & $\begin{array}{l}\text { The reversed Engle coefficient (\%) } \\
\qquad X_{6}\end{array}$ & 61.1 & 0.1459 \\
\hline
\end{tabular}

Table 3 -Values of $X_{i}{ }^{0}$ and $A_{i}$ for Fujian's county areas

Source: Fujian Statistical Yearbook (2008); Data from the second agricultural census of Fujian Province.

I Yu Zhu is Professor and Director, Centre for Population and Development Research, School of Geography, Fujian Normal University, Fuzhou, Fujian Province 350007, China (zhu300@fjnu.edu.cn).

I Min Lin is an officer of the Complaints Bureau of the People's Government of Nanjing County, Fujian Province 363600, China (lmin023@163.com).

I Liyue Lin is a lecturer at School of Geography, Fujian Normal University, Fuzhou, Fujian Province 350007, China (lly30@163.com).

I Jinmei Chen is a masters' candidate at School of Geography, Fujian Normal University, Fuzhou, Fujian Province 350007, China (xiaogolden@foxmail.com). 